\title{
COMPREENDA POR QUE OS VALORES DA GLICOSE SÃO DIFERENTES NAS VEIAS, NOS CAPILARES E NO INTERSTIICIO
}

\author{
UNDERSTAND WHY GLUCOSE VALUES DIFFER IN VEINS, CAPILLARIES, AND INTERSTITIUM
}

DOI - 10.5935/2236-5117.2015v52n3/4a12

Reginaldo Holanda Albuquerque

\section{RESUMO}

O autor apresenta explicações de como os valores da glicose podem ser diferentes de acordo com o local de medição. Mostra como a glicose encontra-se no sangue e no interstício. Como pode influenciar os valores normais da glicose de acordo com o local da dosagem.

Palavras-chave. Glicemia; dosagem; diabetes melito; controle.

\section{ABSTRACT}

The author presents explanations of how glucose values may differ according to the measurement site. He shows how glucose is in the blood and interstitium. How it can influence normal glucose values according to the dosage site.

Key words. Glycemia; dosage; diabetes mellitus; control

\section{INTRODUÇÃO}

Muitos dos usuários dos sensores apresentam nas redes sociais um desencanto com estes dispositivos, pois com frequência os valores divergem com os tradicionalmente obtidos no sangue capilar.

Hoje, neste comunicado, explico as diferenças entre os dois ambientes. 0 sangue é como um rio caudaloso. Percorre todo o corpo em alta velocidade com um volume de 5 litros num homem de $70 \mathrm{~kg}$.

O interstício é como um lago entre as células e tem uma composição química e celular diferente. Sofre influência do meio ambiente com quem através da pele realiza trocas que também ocorrem com o sangue. É mais lento e realiza trocas contínuas muito importantes para a manutenção da homeostase corporal. Veja a figura.

\section{FORMAÇÃO DO LÍQUIDO INTERSTICIAL}

O coração bombeia o sangue para as artérias e devido à pressão hidrostática parte da água é empurrada para fora dos vasos capilares. Esta pressão é denominada de osmótica. Variações desta pressão trazem o líquido de volta para o sistema circulatório. São estas propriedades
Reginaldo Holanda Albuquerque - médico, endocrinologista

Correspondência: SGAS 915, Ed. Advance 1, sala n. ${ }^{\circ} 37$, CEP 70390-150, Brasília-DF. Telefone: (61) 32452759.

Internet: reginaldo.albuquerque@gmail.com

Conflito de interesses: nada a declarar.

Observação: Em atenção à vontade do autor, este artigo não foi editado pela equipe da Brasília Médica.

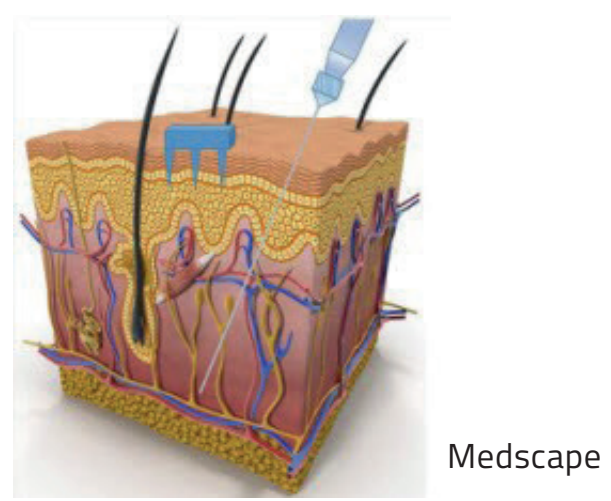

que permitem que medicamentos injetados no subcutâneo, tais como as insulinas, sejam transportados para o corpo inteiro. Além disso, variações nas moléculas dos fármacos alteram o tempo de entrada nos capilares sanguíneos. Todos os diabéticos sabem diferenciar muito bem o uso das insulinas rápidas e lentas.

Além disso, a composição do fluido intersticial pode variar de um local para outro. O líquido peritoneal, por exemplo, é mais claro, tem células menores e um papel lubrificante no abdome. A linfa, também é considerada um líquido intersticial, tem mais leucócitos e combate as infecções. 


\section{FUNÇÕES DO LIIQUIDO INTERSTICIAL}

O sangue, como sabemos, é responsável pela homeostase do organismo. Fornece nutrientes para as células e transportam resíduos das células para outros órgãos, como os rins, onde são eliminados. Os hormônios são transportados por ele e assim dão uma contribuição fundamental para o controle das glândulas. Várias doenças também comprometem o líquido intersticial e alteram a sua funcionalidade.

\section{A UTILIZAÇÃO DE SENSORES NA PELE}

Os sensores de pele vêm ganhando muita importância para o monitoramento de alguns sinais biológicos, como febre, ritmo cardiorrespiratório, presença de suor etc., bem como forma de administração de fármacos. Vários são de uso corrente, como os de reposição hormonal. Em algum momento, não muito distante, teremos uma insulina tópica semi-inteligente que será capaz de perceber a necessidade de aumento ou diminuição da dose aplicada.

Os sensores para a medição da glicose no interstício não são novos. A sua existência permitiu o desenvolvimento das bombas de infusão e até a busca de um pâncreas artificial. São os sistemas denominados de CGMS (monitoramento contínuo de glicose).

Os sistemas do tipo libre começaram a aparecer nos últimos 5 anos e são denominados de sistemas ambulatoriais (AGM) Visam, antes de tudo, o conforto das pessoas que puncionam os dedos várias vezes ao dia. Buscam, ainda, um menor custo quando comparados com as bombas e, sobretudo, um engajamento maior das pessoas nos seus tratamentos. As informações obtidas mostram como um determinado alimento influencia a glicemia. 0 mesmo para o papel da atividade física, das emoções e dos medicamentos.

Mas, quais são os valores de normalidade, ou preditores das complicações como estabelecidos nas várias diretrizes?

As questões básicas são:

- Os valores que devo utilizar são os mesmos das diretrizes tradicionais?

- Por que os valores são diferentes dos que meço no sangue?

- Por que os valores são diferentes se uso o sensor no braço, no abdome, ou no quadril?

- 0 que dizer aos meus pacientes?

- Que países já aprovaram estes sistemas?

- Uso bomba ou estes sensores?

- Por que tem tantos problemas ao fixá-los no corpo?

Algumas destas respostas podem ser encontradas num trabalho de um grupo holandês publicado muito recentemente no número de 5-10-2017 do BMJ e que pode ser lido no seguinte endereço: http://drc.bmj.com. Vale a pena conhecer este trabalho cujo resumo é o seguinte.

Foram estudados 20 indivíduos, 8 do tipo 1 e 12 com o tipo 2 de diabetes. Os sensores caíram em duas pessoas. Estas pessoas receberem dois sensores, um no braço e outro no abdome. Todas também tiveram a glicemia capilar analisada por uma das fitas existentes no mercado. Além disso, estas pessoas foram submetidas a testes de tolerância à glicose. 0 estudo durou 14 dias. As pessoas tinham de 14 a 70 anos de idade.

Achados principais:

1. Os resultados com os sensores mostraram resultados mais baixos do que os obtidos com as glicemias capilares quando os valores estão baixos.

2. Os resultados com os sensores são mais altos quando as glicemias capilares estão mais elevadas.

3. As comparações com as medidas feitas nos braços e no abdome mostram diferenças importantes. Sendo as do abdome $64 \%$ mais baixas do que as do braço.

4. Nos testes de tolerância à glicose a determinação no braço mostrou um aumento mais lento do que os observados nas glicemias capilares medidas com a fita.

Recentemente, a Agência Americana de Regulação aprovou o seu uso. Vários países já estão doando estes sensores aos pacientes do tipo I. O Japão é um deles. Na Austrália estão sendo distribuídos também aos diabéticos do tipo 2 . Na Holanda, França, Canadá e Portugal também.

\section{REFERÊNCIAS}

0 trabalho mencionado anteriormente tem 30 referências sobre o assunto. É importante consultá-lo. Aconselho ainda a visitar um vídeo no youtube no seguinte endereço:

https://www.youtube.com/watch?v=jv41jFFLJvY\&feature=youtu.be Vídeo explicativo:

https://you tube/d9UzbC7pf4E

O sensor por dentro:

https://www.youtube.com/watch?v=sYIm97wjl0o\&t

Incluir alarms:

https://www.youtube.com/watch?v=784xXdcDohs

https://youtu.be/JqxoOERkuDI

The Blucon also works with Glimp: https://play.google.com/store/

apps/details?id=it.ct.glicemia

Como estender além de 14 dias:

https://www.youtube.com/watch?v=JqxoOERkuDI\&t=417s

Como reusar:

https://www.youtube.com/watch?v=PTNqPcffDIY

Medindo a acuracidade:

https://www.youtube.com/watch?v=iMZQjIUICj4

Testando os sensores:

https://www.youtube.com/watch?v=iMZQjIUICj4 